These stinging insects, nuisances as well as agricultural pests, can be controlled through intensive and extensive measures.

\title{
The Imported Fire Ant
}

\author{
F. G. FAVORITE, M.P.H.
}

$\mathrm{T}$ THE IMPORTED fire ant (Solenopsis saevissima richteri Forel) (1), of concern to agriculture in the southeastern United States, is also a public health nuisance. Its sting is almost as painful as a honeybee's and can cause an anaphylactoid reaction.

These stinging ants, now reported in North Carolina, South Carolina, Georgia, Florida, Alabama, Mississippi, Arkansas, Tennessee, Louisiana, and Texas, were first introduced into the United States at Mobile, Ala., around 1920 (fig. 1). Presumably the ants gained entry into the country as stowaways on vessels arriving from South America, the normal habitat of this species (2).

The imported fire ant cannot and is not being ignored. To control it, the Federal Government has designated $\$ 2,400,000$ in matching funds for States that suffer from infestations. Alabama has allocated $\$ 155,000$; Georgia, $\$ 250,000$; and bills for funds have been presented in other State legislatures. Both intensive and extensive measures will be required to halt this insect short of its geographic reproduction limit.

The imported fire ant is not unlike many other ants in general appearance, but it differs considerably in habits and microstructure. The fire ants are classed as medium sized. The worker minors, females of immature colonies, average approximately $1 / 8$ inch in length, whereas the worker majors, females, usually sterile, of mature colonies, average $1 / 4 \mathrm{inch}$.

Captain Favorite, MSC, U. S. Army, is chief of the Entomology Section, 3d Army Medical Laboratory, Fort McPherson, Ga.
'The basic color varies by geographic location from rust red to dark brown.

Identification of the imported fire ant is dependent upon careful examination to separate it from closely related species of the genus Solenopsis. The major form of S. geminata, the tropical fire ant, has an extremely large head out of proportion to the rest of the body and mandibles usually without teeth. Its antennal scape (the first segment of the antenna) reaches only one-half to two-thirds the distance to the posterior margin of the head. In the major form of $S$. xyloni, the southern fire ant, the mandible usually has three teeth and its antennal scape does not extend beyond two-thirds the distance to the posterior margin of the head.

The major form of S. saevissima richteri, the imported fire ant, normally has four mandibular teeth, and its antennal scape extends two-thirds or more the distance to the posterior margin of the head (fig. 2).

\section{Biology}

The imported fire ant's nest, or mound, also identifies it, for these ants do not build an elevated mound with the central entrance common to many other species. Fire ant mounds vary in construction to suit the environment. When the colony is free to develop without interference, the mound grows to a height of 18 to 24 inches with a basal diameter of approximately 24 inches. The active mound becomes hard in texture after alternate wetting and baking from exposure. The hardened mounds have caused damage to farming equipment $(3,4)$. When colonies develop in lawns where they 
Figure 1. Spread of the imported fire ant in the southeastern United States, 1918-57.

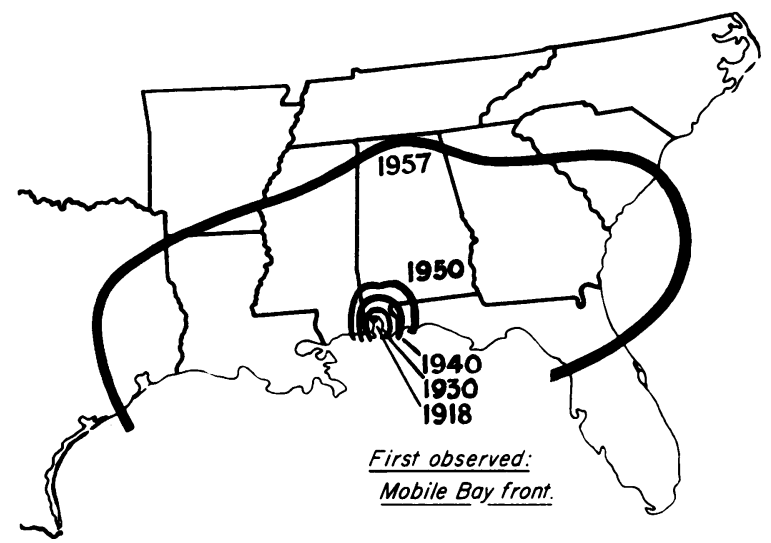

U. S. Department of Agriculture

are frequently disturbed by grass-cutting equipment, the ants modify the architecture of the mound to a spreading nest, irregular in shape, covering 3 to 5 square feet, and rarely more than an inch or two high. On slopes where grass cutting is infrequent, the colonies usually select a hillock or a raised clump of weeds for the mound. When it is repeatedly disturbed or when its food supply becomes scarce, the colony moves to a new location, usually within 25 feet of the original site. Or the colony divides into 2 or 3 smaller ones, and the ants rebuild each colony to maximum strength.

Mature fire ant colonies house as many as
25,000 insects. In the colonies I observed, the greatest proportion of the ants were worker majors equipped with a pugnacious temperament and competent stinging apparatus. Several queens may be in the same colony.

In feeding habits the ants are practically omnivorous. Primary food is obtained from the seedlings, roots, and subsurface portions of plants and grasses (3-5). There are also records of ants attacking clutches of eggs, entering the pipped eggs, and feeding on the young within $(4,5)$.

\section{Effect on Persons}

When the fire ant mound is disturbed, the insects bubble forth in the thousands and within seconds the colony can administer 3,000 to 5,000 stings on an invader. The ants move rapidly, sting almost immediately on contact with the skin, and are prone to sting 3 or 4 times.

Normally, the ant seizes with its mandibles an anchor on a hair or the skin, quickly moves the abdomen under itself, and drives the stinger into the skin. The stinger remains implanted for 3 to 7 seconds before it is withdrawn, and the ant either pivots on its mandibular anchor or moves a short distance to repeat the stinging process. Second and third stings are usually of less duration but still quite painful.

Reports have said that the ant uses its mandi-

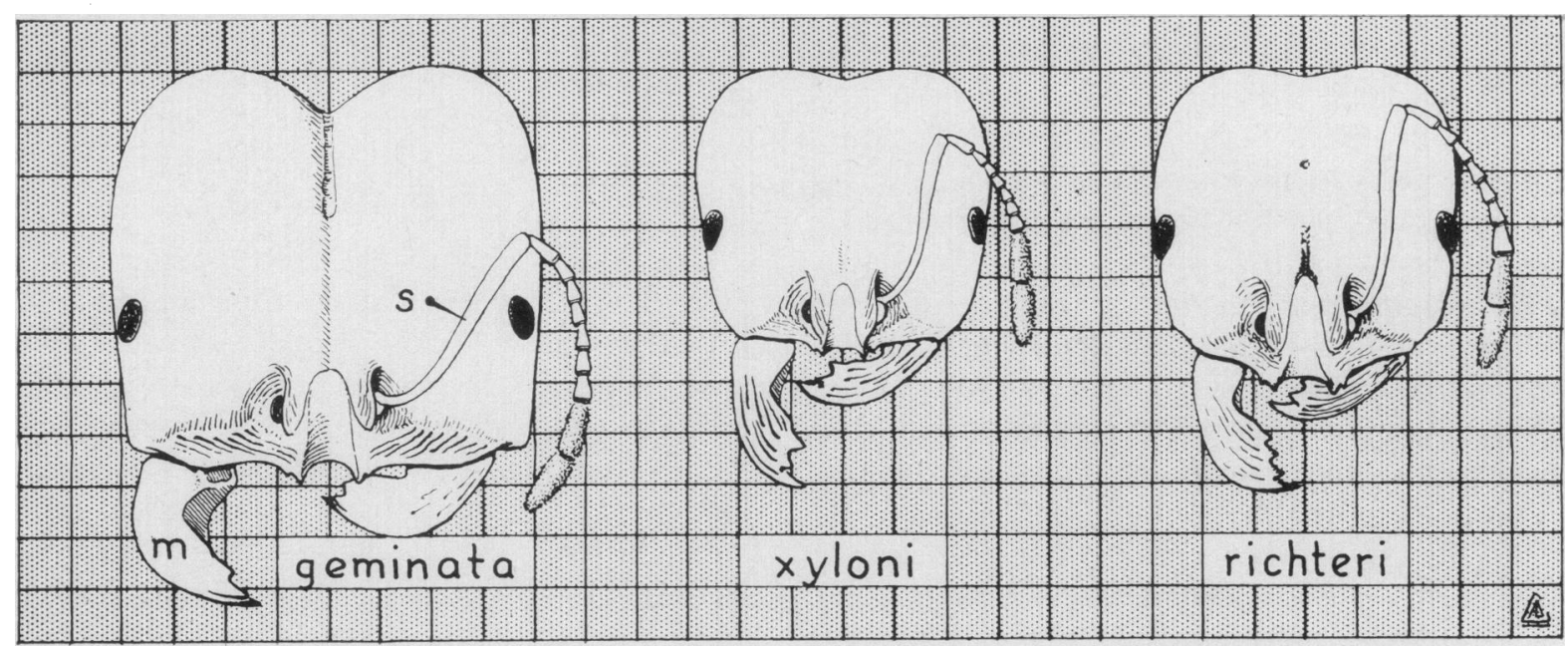

Figure 2. Distinguishing characteristics of three species of Solenopsis: S. geminata the tropical fire ant, S. xyloni the southern fire ant, and S. richteri the imported fire ant $(m=$ mandible, $s=$ scape). 
bles to make an incision to receive the stinger (5). My observation of stings received while preparing this study differs from these reports; discrete stings were received while the mandibular anchor was retained.

Insertion of the stinger brings immediate pain almost comparable to the sting of a honeybee. Within several minutes a wheal, 4 to 8 $\mathrm{mm}$. in diameter, appears. The stinging sensation usually subsides by the time the wheal appears. Within 24 hours a pustule, 2 to $3 \mathrm{~mm}$. in diameter, forms in the center of the wheal. The pustule persists for 3 to 8 days until the purulent material is absorbed or sloughed. Each sting leaves a smooth pink area 2 to $4 \mathrm{~mm}$. in diameter for several weeks until the gradual formation of scar tissue takes place (fig. 3).

During $1957^{\circ}$ at Fort Benning, Ga., where most of my observations were made, approximately 300 persons, mainly dependents of military personnel, reported for medical care of imported fire ant stings. The majority of these persons received their stings on the lower leg and forearm while they were working or playing near their residences.

Five persons, 2 adults and 3 children, manifested anaphylactoid-type reactions. One girl reacted severely to a fifth sting, although she demonstrated no sensitivity to any of four previous stings. Following the fifth sting she suffered total body edema, cyanosis around the mouth, and respiratory embarrassment. An adult male fainted 3 times shortly after receiving 4 stings about the ankles. On examination hives were observed.

Treatment of children by parenteral route with $1: 1,000$ epinephrine graduated in dosage from 0.1 cc. in infants to $1.0 \mathrm{cc}$. when the child's weight exceeds 100 pounds, and of adults with 1.5 cc. of injectable benadryl solution (15 mg.) by deep intramuscular route, plus oral administration of antihistamines in both groups, has been successful in controlling most reactions to fire ant stings.

While this study was being prepared, a second instance of imported fire ant infestation of a military installation occurred at Fort McPherson, Ga., approximately 100 miles from Fort Benning. The ants were observed by a medical officer who had attended an orientation on the problem some 10 days earlier. Because

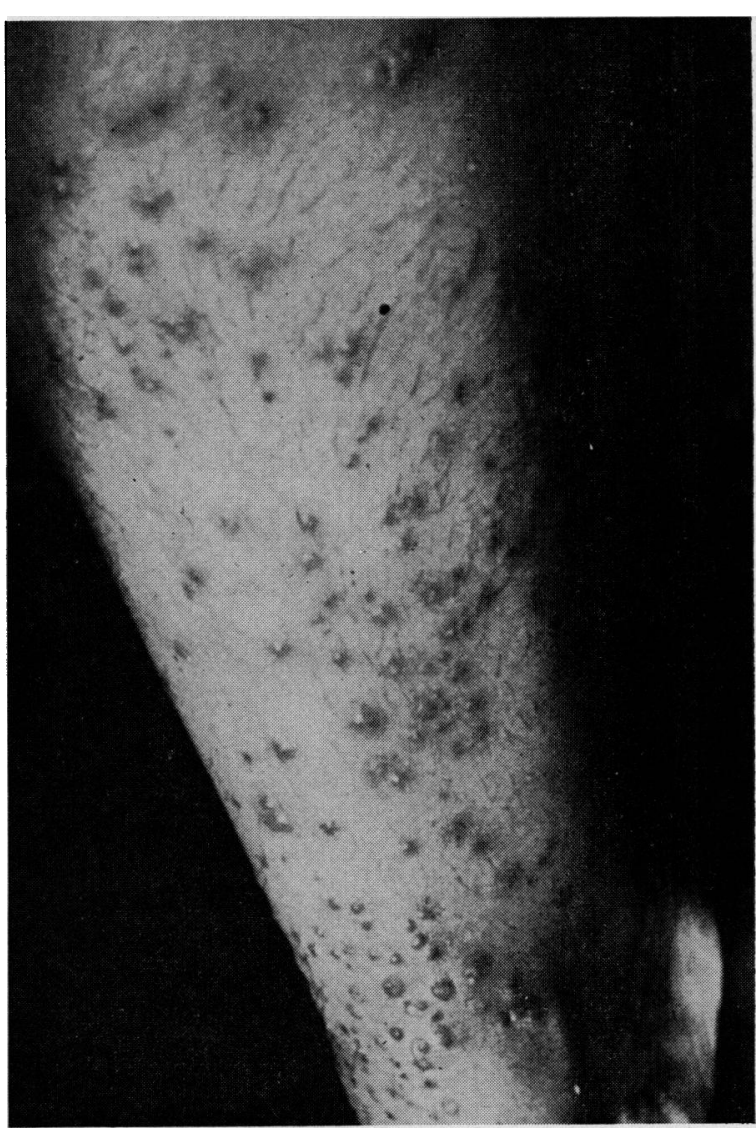

Dr. V.J. Derbes and Dr. R. C. Jung Tulane University School of Medicine

Figure 3. Fire ant stings at $\mathbf{7 2}$ hours.

it had been quickly identified, the colony was treated while it was still immature, the majority of the ants being worker minors; it is believed that the infestation was eradicated before it had the opportunity to spread.

Even so, in the 24 hours between discovery and treatment the colony had moved approximately 4 feet from the original site. Considerable motor vehicle travel between the two military posts clearly provided a means of transportation for the imported fire ant. Local increases also occur during the spring mating season when the winged queen, having mated in flight, starts a new colony wherever she alights.

\section{Control}

Granular formulations of hydrocarbon insecticides seem to offer more promise for control than any other method. Both dieldrin and heptachlor at 5 percent concentration, spread 
at the rate of 40 pounds per acre, obtaining 2 pounds of technical material per acre, were successfully used during the summer of 1957. Chlordane has been used at the rate of 4 pounds of technical material per acre $(6-8)$. Seeding machinery or another type of equipment which affords an even coverage can be utilized for spreading. I feel that watering the ground following treatment is essential to gain dispersion of the chemical and reduce the toxic hazard to human beings and domestic animals.

In addition, mounds should be treated individually by excavation, direct insecticide application, and watering. However, mound treatment alone cannot be relied upon for eradication. Following such treatment the ants move from the immediate area and the survivors establish a new colony.

Previously treated areas indicate that the method of spreading and treating mounds individually with insecticides will prove effective for at least 2 years ( $y)$, when preventing reinfestation may be necessary. 'The cost of the control program will vary with the insecticide selected, method of application, and the cost of labor in the community, but experience indicates that an average figure in the southeast would be approximately $\$ 5$ per acre.

The use of a toxic chemical introduces an- other public health hazard, but if the chemical is applied by qualified personnel under proper supervision, the hazard can be nullified.

\section{REFERENCES}

(1) Creighton, W. S.: The new world species or ine genus solenopsis. Proc. Am. Acad. Arts \& sc. (66) : $87-89$ (1930).

(2) Eden, W. G., and Arant, F. S.: Control of the imported fire ant in Alabama. J. Econ. Fnt. 4:2: 976-979, December 1949.

(3) Blake, G. H., Jr., and others: Control of the imported fire ant in the black belt area of Alabama. Preliminary report. Auburn. Alabama Polytechnic Institute, Agricultural Experiment Station. April 19:56.

(1) Foster, J.: Secrets of the fire ant. Miss. Game \& Fish 20 : 4-5, July 195i.

(.) L. S. Department of Agriculture: The importerl fire ant, how to control it. Department of Agri(rulture Ieaflet No. 350. Washington. I). C., C. S. Government I'rinting Office. March 19:4t.

(6) Hutchins, R. F., and Green, H. B.: The imported fire ant. Mississippi Agricultural Experiment Station, Information Sheet $\mathbf{5 6 2}$. State College. Miss., May 19:7.

( $i)$ Blake, G. H., Jr.: Imported fire ant; On the march in Alabama. Highlights Agric. Res. 3: 5, Fall 1956.

(8) Arant, F. S., and Eden. W. G: Control of the imported fire ant. Alabama Polytechnic Institute. Prog. Rep. Series No. 4\%. Auburn, December 1949.

\section{Environmental Engineering Curriculum}

Rensselaer Polytechnic Institute in Troy, N. Y., will offer full programs in the newly developed field of envirommental engineering beginning in the fall of 1958 .

At that time, a 4 -year undergraduate curriculum leading to the degree of bachelor of environmental engineering and graduate courses leading to advanced degrees will be put into effect.

The object is to train engineers to meet environmental problems created by a growing population, industrial expansion, and increased urbanization.

Water conservation, food supply, air pollution control, and problems associated with the nuclear industry will be studied. Other courses will deal with industrial safety, waste treatment and disposal, housing, insect and rodent control, and research.

The new curriculum was developed in consultation with engineers and health officials at all levels of government. 